\title{
Organizational Socialization through Employee Orientations at North Carolina State University Libraries
}

\section{Angela Ballard and Laura Blessing}

\begin{abstract}
North Carolina State University Libraries has built a strong employee orientation program based on the belief that early socialization contributes to the success of new employees. Its orientation model includes a focused orientation session, a checklist, and individual meetings with key library faculty and staff. All aspects of the orientation focus heavily on socialization factors such as understanding the Libraries' mission and values, meeting key people within the organization, and becoming acquainted with other new colleagues. This paper details the Libraries' orientation approach and the research that supports it.
\end{abstract}

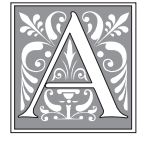

s libraries hire new employees, it is important for managers to pay close attention to socialization factors. Organizational socialization is the process by which employees learn about and adapt to new jobs, roles, and the culture of the workplace. ${ }^{1}$ Early socialization factors may indicate a new employee's job satisfaction and influence his or her longevity in the organization. When a new library employee is hired, retention of that employee is crucial, especially when considering lower numbers of qualified applicants for librarian positions. ${ }^{2}$ Formalized socialization may be even more important for new hires coming from diverse backgrounds. ${ }^{3}$ Documented underrepresentation of ethnic minority professionals in academic libraries has caused several academic libraries to pay closer attention to minority recruitment and retention. ${ }^{4}$ Library administrators who strive to hire and retain a more diverse workforce should therefore carefully consider socialization issues.

Formal socialization practices also can have many benefits of interest to management. For instance, they have been linked to increased organizational commitment, job involvement, role orientation, and tenure. ${ }^{5}$ Management literature stresses that when managers fail to use the first weeks to promote corporate values, employees educate themselves on corporate values through more informal means. "No [organization] should hire a new employee without a systematic program that exposes the new employee to all aspects of the business the first few months." ${ }^{\prime 6}$ Research studies have shown that orientation programs "reduce turnover and absenteeism, 
prevent performance problems, instill positive attitudes about the organization, and pave the way for better communication between the supervisor and the new employee." ${ }^{\prime 7}$ Few library managers would scoff at such positive outcomes.

\section{Socialization and Job Satisfaction}

Several motivation models have been used to study job satisfaction. For instance, Maslow's hierarchy of needs theory postulated that, first, physiological and, then, safety needs must be fulfilled before belongingness and love needs emerge. When belongingness and love needs were satisfied, the individual's higher-level needs, first esteem and later self-actualization, would emerge. ${ }^{8}$ Maslow believed that few people achieve the self-actualization level of the hierarchy. If we relate Maslow's hierarchy of needs to organizational socialization theories, we see that belongingness and love needs closely relate to what organizational sociologists call socialization factors. Socialization needs, therefore, must be fulfilled before needs for esteem and self-actualization emerge.

Another theorist, Herzberg, looked at motivators and their relationship to job satisfaction. Herzberg viewed interpersonal relations as a more basic, or what he called a "hygiene," category. In his theory, hygiene issues such as interpersonal relations must be met at a basic level before the employee can feel satisfied with the job. In reviewing job satisfaction of library workers, Gail K. Dickinson compared Maslow's and Herzberg's motivation models with Alderfer's Existance, Relatedness, Growth Theory to underscore the importance these factors have on job satisfaction. ${ }^{9}$ She grouped Alderfer's "relatedness" with Herzberg's "recognition, interpersonal relations, and supervision" needs and Maslow's "esteem, love, and safety" needs.

Dickinson stated that factors such as the relationship between administrator and worker have more of an effect on job satisfaction than salary. ${ }^{10}$ Although the presence or absence of an employee orientation may not directly result in job satisfaction, orientation programs that emphasize socialization factors may be indirectly linked to job satisfaction. Employers may find that an effective socialization process enables new employees to have more autonomy and establish positive relationships.

\section{Organizational Socialization through Employee Orientations}

During the employee's first weeks on the job, an understanding of the organization's culture is formed. This period can be an impressionable one for the employee. When employees are new, adjustment issues may be more intense, so they may need more attention and reassurance. Regardless of whether or not a formal socialization program exists, employees eventually become socialized. Creating a systematic socialization program such as an orientation process gives management more influence over how the employee adapts to a new job and relates to others in the new work environment. Richard E. Rubin referred to the "psychological condition of excitement and high commitment" that is present at the beginning of employment as "a perfect time to orient and train employees."11

To understand an organization's culture, a person new to the organization must be able to recognize the organization's values and beliefs, observe employee relations, and appreciate the organization's history, customs, and rituals. Other clues to an organization's culture can be found by observing the language, its physical environment, and the way time is valued and used. ${ }^{12}$ Although some of these elements of culture are articulated specifically in presentations or activities during a formal orientation session, others are modeled by the staff involved in all aspects of the orientation program. In designing an orientation program, developers should look for opportunities to ensure that the orientation experience accurately reflects the organization's values and culture. 


\section{A Model for Library Orientation}

Orientation efforts at NCSU began with a simple orientation checklist and later were developed into a comprehensive program based on research that suggests that structured orientation and socialization efforts can impact employee satisfaction and, ultimately, organizational success. The result is a multifaceted approach to employee orientation that includes a scheduled orientation session as well as tools and support for managers and supervisors in welcoming and orienting new employees to the work environment and organizational culture.

\section{Background/History}

The evolution of the program occurred in stages, each placing greater emphasis on the socialization aspects of the orientation process. The NCSU Libraries implemented the first standard orientation checklists in the mid-1990s. The checklists served to remind supervisors of key policy, safety, and procedural information to communicate to new employees. This effort helped to document compliance with government and university policies regarding communication of specific policies and created more consistency in what information was given to new employees across library departments.

In the late 1990s, the Libraries formed a Staff Learning and Development Committee (SLDC) to explore staff development needs and to plan a training and development program that would facilitate organizational learning and flexibility. The committee quickly identified employee orientation as a key component of a successful staff development program and revised the existing orientation checklists to broaden their scope. The revised checklists included reminders to supervisors about important steps to take in preparing for the new employee's arrival and welcoming the employee during the first weeks. Items covered in the first two weeks emphasized orientation to the work environment and socialization. Informational items were grouped into categories with guidelines on which information to cover during each of the first four weeks of employment.

In 1998, the Libraries appointed a fulltime librarian for staff development and diversity initiatives who also served on both the SLDC and the Library Diversity Committee. One of the first assignments for the new position was to communicate the Libraries' commitment to diversity initiatives through a required diversity information session for new and existing employees. Discussion and planning for a "diversity orientation" session served as the catalyst for development of a broader employee orientation program. The staff development librarian and the SLDC developed mandatory orientation sessions for all new employees and implemented them in 1998.

These orientation sessions, offered once a month for a full day, consisted of a series of tours, presentations by representatives of departments, a short diversity program, and informational sessions on work policies. SLDC members facilitated the sessions, and the staff development librarian coordinated scheduling and communications and facilitated the diversity session and other sessions, as needed. This delivery model created a more dynamic atmosphere than a single facilitator would have been able to achieve. The objectives for the program were to orient new employees to the physical spaces and service areas, to have them meet employees in various departments, to make an early statement about the importance of diversity concerns, and to ensure that they had been exposed to library work policies.

Employee response to the scheduled orientations was positive overall, and the program continued to evolve based on specific feedback from participants. Each iteration of the program reflected the continuing shift in purpose from a largely informational program to one that introduced and emphasized organizational philosophy and culture. In 2000, the committee introduced a new, highly interactive approach to orienting staff to 
the Libraries' mission, vision, and values. This marked the most fundamental change in the tone and purpose of orientation. Personnel staff and SLDC members fully embraced the idea that the primary purpose of the formal orientation session is one of socialization. Most other aspects of the orientation process could be facilitated using other means such as orientation checklists, training for supervisors on welcoming new employees, improvement of systems for ensuring that employees have the tools they need to be productive on the first day of work, and a relevant, reliable, and current online source of information for new employees.

\section{The Orientation Program}

The current orientation program consists of three components: (1) library orientation sessions that focus on library culture and values, (2) orientation checklists that ensure that supervisors meet expectations for welcoming new employees and covering policy and procedural information, and (3) one-on-one meetings with appropriate individuals.

\section{Orientation Sessions}

Scheduled library orientations are offered in each month that more than three new employees have joined the staff. The orientations are made up of a series of interactive sessions and tours for a total of four-and-a-half programmed hours. (See appendix A.)

In a welcoming session, a facilitator covers the day's agenda and program objectives and leads an exercise for introductions. The second session introduces the Libraries' mission, vision, and values statements. This second session is the most central to the program's socialization objective and also is the most interactive. Participants are divided into two groups that compete in activities designed to help them "discover" the mission and vision statements together. In the first activity, the teams are given five to seven minutes to construct a mission statement for the organization using a version of the actual statement with key words missing and a collection of possible words to use. The facilitator then reads the mission statement, asking the teams to supply the words. The significance of each phrase in the mission statement is discussed as each is "revealed," and examples are given of current projects or initiatives across the Libraries that represent the organization's commitment to its mission.

The second activity is designed to introduce the vision statement. The teams discuss and answer a series of factual questions about the Libraries with numerical answers. The winners in each round guess letters in a hangman-type game that gradually uncovers the short vision statement. The answers to the questions are statistics that illustrate the size and scope of the Libraries' services and collections. The facilitator provides background and context for questions throughout the activity. Finally, the employees are given copies of the Libraries' official mission, vision, and values statements and are asked to discuss how these statements are relevant to their roles in the organization.

A critical component of the monthly program is a session titled "Welcomed, Valued, Respected," which emphasizes the Libraries' broad definition of diversity, reinforces the organizational value of inclusiveness, and describes campus and library diversity initiatives. The purpose of this session is to make a clear statement about the role of diversity in the organization's success.

A short session titled "Life Cycle of Library Resources" illustrates work flow and relationships between departments. Whereas the program generally highlights the innovations and initiatives that characterize the organization's progressive culture, this session provides an opportunity for facilitators to emphasize the importance of the basic functions of libraries. Participants are encouraged to share what they know about the kinds of work done in their own departments. This session is important in providing context 
for the walking tours that follow it and is particularly valued by employees who have little or no experience in academic libraries.

The final substantive session is an overview of the Libraries' staff computing environment. This overview is designed to emphasize the Libraries' investment in technology and digital library initiatives and to convey the organization's commitment to supporting staff in adopting and using technology. The facilitator reviews the range of available networked resources and the help desk and training services provided by the systems department. To reinforce the intranet as a starting point for staff information, intranet pages are used as the backdrop for all talking points and employees are encouraged to explore the site at lab computers during the session.

Tours of the main library building are a key component of the orientation sessions. Scripted tours, led by SLDC members, are designed to go beyond orienting staff to the physical space. Employees are led through offices, departments, and service areas as the guide describes projects and initiatives that are under way in various areas that support the Libraries' mission. A few locations or service points are highlighted with extended stops and short presentations by staff working in those areas. In past versions of the orientation program, representatives from every department or unit spoke to the orientation group for three to five minutes each. The most consistent feedback about the orientation program was that the tours were too long and tedious; making it difficult for participants to know what information was most important to retain. Rethinking the tours was a significant effort that has proved to be very worthwhile. Although new employees still receive a tour of the physical space, creating a more stimulating experience enhances the socialization aspect of orientation.

Finally, a Libraries' Safety Committee representative meets briefly with each orientation group to present mandatory safety information. Including the safety session ensures that the Libraries meets its obligation to share this critical information and reinforces the program's underlying theme that staff well-being is a top priority in the organization. Because the orientation program promotes a feeling of openness, an added benefit to including the safety session is that questions generated during this session sometimes reveal issues of concern to staff that might not be readily raised in other forums.

Beyond the structure and content of the sessions, other factors help create a purposeful and positive socialization experience. The overall tone of the sessions is light and fun, but facilitators display professionalism and respect as well. Although a single person best facilitates short sessions, having another member of the coordinating group present adds richness to the session dynamics. Feedback from participants indicates that this practice also may send a subtle message that the organization cares enough about the orientation experience to invest significant staff time in it.

The decision was made early in the development of the program to orient librarians and support staff together. Because the primary purpose of the orientation program is socialization to the organizational culture, the experience is relevant to staff at all levels. In some cases, employees report that a cohort bond is initiated during orientation that continues beyond the orientation period. By orienting all staff together, the program establishes an early example of the spirit of inclusiveness and collaboration that it aims to foster throughout the organization.

\section{Orientation Checklist}

Information specific to a particular position level, department, or job function is, of course, vital to the orientation process and is covered by supervisors guided by the orientation checklist. Early versions of the checklist were simply lists of employment policies and procedures. Later versions were developed to be 
more compatible with the socialization goals of the overall orientation program. The orientation checklist is now a more meaningful tool, providing support for supervisors in managing the orientation process. The structure of the checklist reflects the work of motivational theorists in that items focused on employee feelings of physical and emotional security are addressed first. Information or experiences that enhance feelings of relatedness and opportunities for productivity and growth then are incorporated gradually over a four-week orientation period. (See appendix B.)

The checklist represents the organization's expectations for consistency in the experience of new employees across departments and supervisors. Even before a new employee arrives, the checklist is used to prepare for orientation. The list is available online so that supporting policy manuals, Web sites, and other documents can be linked to checklist items. This relieves the burden on supervisors of assembling orientation packets and encourages the employee reliance on the intranet as a rich and current information resource. When supervisors take this part of the orientation process seriously, they model employee awareness, confidence, and well-being as organizational values.

\section{Individual Meetings}

In addition to the scheduled orientation sessions and the checklist, the orientation program involves individual meetings with key library faculty and staff. All employees meet with the appropriate personnel representative on the first day of employment. Librarians are scheduled for meetings with key individuals to learn about the organization's expectations with regard to internal and external communications, fiscal responsibility, and accountability. An early meeting with the associate director for the employee's division offers a big-picture perspective on the employee's role in the division and an opportunity to establish a rapport with the administrator that might not occur as easily in the course of other types of meetings. Department head level managers also meet with each of the other department heads during the first six weeks or so of employment.

\section{Evaluation and Assessment}

Maintaining a commitment to the goal of socialization through orientation requires ongoing evaluation and development of the program. However, there are several problems with a formal evaluation of a program of this type. It is difficult to measure the impact of an orientation program quantitatively because possible measurable indicators of success such as tenure and productivity are impacted by many other factors within the organization and the profession. In addition, when participation in an orientation program is mandatory, it is impossible-and certainly not in the best interest of the organization-to use a control group to evaluate the program's effectiveness.

Assessment efforts thus far have focused on systematic reviews of program content and on participants' evaluations of the scheduled sessions. The staff development librarian and members of the SLDC regularly review the checklist and session materials to ensure that the content is current and relevant to the objectives of the program.

Participants in the orientation sessions answer a series of open-ended questions about their reactions to key components, their overall orientation experience, and suggestions for improvement. The resulting qualitative feedback is critical to the development process. Major revisions to the program content and structure have been prompted by participant feedback.

The next step in more formally assessing the program is to conduct structured follow-up interviews with new staff after they are established in their positions. The goal of such a study is to determine whether staff members believe that the orientation experience has impacted their readiness to work in the organization and/or their overall job satisfaction. 


\section{Ongoing Developments}

Recognizing the organic nature of the orientation program is key to keeping it fresh and relevant. The SLDC and staff development librarian routinely review session evaluations and feedback about the program and readily make needed adjustments. Changes to program content or structure in response to changes in the organization are implemented quickly to keep the program current.

Recent development efforts are focused on increasing support for the managers and supervisors who strongly influence an employee's early socialization. Personnel librarians are developing a short workshop for supervisors on how the organization's expectations in welcoming new employees and how to incorporate organizational values into the presentation of materials referenced on the orientation checklists. The information technology training librarian is further developing a set of tools to standardize the content, delivery methods, and language used by departmental computing consultants and systems staff in presenting computing information to new employees. In addition, the SLDC is exploring the possibility of providing lunch for participants during the scheduled orientation program in the hope of adding a primarily social component to the day.

The Libraries also is developing a new program in which each new staff member will be paired with an "orientation partner" outside his or her assigned department. The partner will contact the new employee within the first weeks of employment to arrange a meeting or lunch to talk about any concerns or questions the new employee may have. There may be one or two follow-up meetings to ensure that any outstanding questions or concerns have been fully addressed.

\section{Orientation as Part of a Process}

Orientations should be the beginning of a staff development process that lasts throughout the individual's employment.
Although employee orientations assist with the socialization process, they alone will not increase organizational commitment. ${ }^{13}$ For the orientation experience to have lasting value, employees should see ongoing evidence that their professional development is valued. This can be demonstrated by offering relevant, high-quality staff development programs and by communicating regularly with the employee about his or her specific development needs. Building a positive relationship between employee and supervisor should be a goal of orientation, paving the way for future dialogue about training and development.

\section{Conclusion}

The NCSU Libraries has developed an employee orientation program based on organizational socialization theory and research. The process involves a formal orientation program for all new staff, an orientation checklist that provides a framework for a four-week orientation process managed by the supervisor, and a series of meetings with key individuals in the organization. The goal of this approach is to purposefully and consistently meet the basic needs of new employees by creating a sense of physical and emotional security and by fostering the relatedness and role orientation that researchers and theorists have tied to job satisfaction.

Response to the orientation process from employees, supervisors, and administrators has been very positive. Written evaluations and anecdotal evidence suggest that employees feel that the socialization aspects of the orientation program are valuable in helping them to acclimate to the organization's culture, understand its language and values, and build relationships. However, additional study is needed to determine whether the application of socialization theory to the development of an employee orientation program has a measurable impact on individual job satisfaction or organizational success. 


\section{APPENDIX A \\ NCSU Libraries Orientation Agenda}

$\begin{array}{ll}\text { 9:00-9:30 } & \text { Welcome \& Introductions } \\ \text { 9:30-10:10 } & \text { The Libraries' Mission, Vision \& Values } \\ \text { 10:10-10:25 } & \text { Break-NCSU Librarians Association } \\ \text { 10:25-10:50 } & \text { Welcomed, Valued, Respected } \\ \text { 10:50-11:00 } & \text { Life Cycle of Library Resources } \\ \text { 11:00-11:30 } & \text { First Tour } \\ \text { 11:30-12:00 } & \text { NCSU Libraries' Computing Environment } \\ \text { 12:00-1:30 } & \text { Lunch } \\ 1: 30-1: 40 & \text { NCSU Libraries' Staff Association } \\ 1: 40-1: 50 & \text { Safety Information Session } \\ 1: 50-2: 45 & \text { Second Tour } \\ 2: 45-3: 00 & \text { Wrap-up/Final Exam }\end{array}$

\section{APPENDIX B \\ NCSU Libraries Employee Orientation Checklist Categories}

\section{BEFORE START DATE}

I. Preparing the Workspace

II. Schedule Meetings and Training Sessions

III. Equipment Installation \& Configuration

\section{WEEK ONE}

I. The Basics

II. Safety and Security

III. Telephones/Copies/Supplies/Mail

\section{WEEK TWO}

I. The Libraries' Mission, Vision, and Organization

II. Performance Expectations: Tools and Policies

III. Employment Policies

IV. Attendance and Leave

V. Communication and Publications

\section{WEEK THREE}

I. The Libraries: Departmental Role and Customer Service Principles

II. Performance Expectations: Work Planning and Goal Setting

III. Development and Training Opportunities

WEEK FOUR:

I. Scheduled Meetings

II. Follow-up 


\section{Notes}

1. Howard J. Klein and Natasha A Weaver, "The Effectiveness of an Organizational-level Orientation Training Program in the Socialization of New Hires," Personnel Psychology 53 (2000): $47-66$.

2. Joe Hewitt, Barbara B. Moran, and Mari E. Marsh, "Finding Our Replacements: One Institution's Approach to Recruiting Academic Librarians," portal: Libraries and the Academy 3 (Apr. 2003): 179.

3. Talya Niehaus Bauer, Elizabeth Wolfe Morrison, and Ronda Roberts Callister, "Organizational Socialization: A Review and Directions for future Research," Research in Personnel and Human Resources Management 16 (1998): 149-214.

4. Mark Winston, "The Role of Recruitment in Achieving Goals Related to Diversity," College E Research Libraries 59 (May 1998): 240-47.

5. Natalie J. Allen and John P. Meyer, "Organizational Socialization Tactics: A Longitudinal Analysis of Links to Newcomers' Commitment and Role Orientation," Academy of Management Journal 33, no. 4 (1990): 845-58; Bauer, Morrison, and Callister, "Organizational Socialization"; Cynthia D. Fisher, "Organizational Socialization: An Integrative Review," Research in Personnel and Human Resource Management 4 (1986): 101-45.

6. Darrel W. Ray, "Important Impressions: You Only Get One Chance to Influence a New Employee," Management World 17 (Mar./Apr. 1988): 34-35.

7. Claudia Reinhardt, "Training Supervisors in First-day Orientation Techniques," Personnel 65 (June 1988): 24,26,28.

8. Abraham Maslow, Maslow on Management (New York: John Wiley \& Sons, 1998).

9. Gail K. Dickinson, "A New Look at Job Satisfaction," Library Administration \& Management 16, no. 1 (Winter 2002): 28-33.

10. Ibid., 29.

11. Richard E. Rubin, Hiring Library Employees: A How-to-do-it Manual. (New York, London: Neal-Schuman Publishers, 1993).

12. Jennifer Burkhart, "Understanding Organizational Culture" (Colorado State Department of Education, 1995). ED 399437.

13. Klein and Weaver, "The Effectiveness of an Organizational-level Orientation Training Program." 